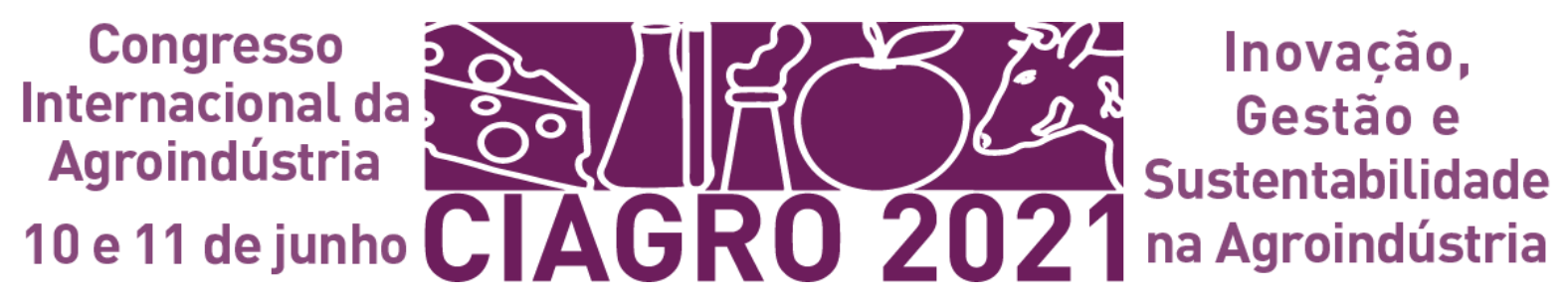

\title{
ANTIMICROBIANOS NATURAIS NA CONSERVAÇÃO DE ALIMENTOS - UMA REVISÃO
}

\section{ANTIMICROBIANOS NATURALES EN LA CONSERVACIÓN DE ALIMENTOS - UNA REVISIÓN}

\section{NATURAL ANTIMICROBIALS IN FOOD CONSERVATION - A REVIEW}

\author{
Éllen Francine Rodrigues ${ }^{1}$; Afonso Henrique da Silva Júnior ${ }^{2}$; Carlos Rafael Silva de Oliveira ${ }^{3}$; Luís Antonio \\ Lourenço $^{4}$; Lisandro Simão ${ }^{5}$
}

DOI: https://doi.org/10.31692/IICIAGRO.0269

\section{RESUMO}

A produção de alimentos seguros e de alta qualidade tornou-se um desafio para a indústria de alimentos, devido a deterioração dos alimentos, que é causada pelo crescimento indesejável de microrganismos patogênicos/deteriorantes. Essa deterioração pode levar à perda e ao desperdício dos alimentos. Para a redução das perdas a indústria de alimentos utiliza conservantes sintéticos para controlar o crescimento microbiano com o intuito de estender a vida útil de prateleira, a qualidade e a segurança dos alimentos. No entanto, alguns aditivos químicos quando ingeridos em grandes quantidades podem causar reações indesejáveis aos consumidores. $\mathrm{O}$ aumento da preferência dos consumidores por aditivos alimentares mais naturais e a preocupação com a segurança dos conservantes sintéticos incentivaram a indústria de alimentos a procurar alternativas ecologicamente corretas. Assim, surgiu o intuito de substituir o uso de conservantes sintéticos tradicionais por antimicrobianos naturais nos alimentos. O presente trabalho tem como objetivo apresentar alguns conservantes naturais com propriedades antimicrobianas, enfatizando a importância do seu uso na produção de alimentos e possíveis aplicações em alimentos. Além disso, uma classificação baseada na origem dos antimicrobianos naturais é apresentada considerando as fontes de origem para as principais categorias: plantas, animais e microbiana. As propriedades antimicrobianas dos compostos de origem natural devem-se principalmente à presença de bioativos (como os ácidos fenólicos, terpenos, aldeídos e flavonoides, entre outros). Essas substâncias bioativas podem ser considerados uma alternativa viável para resolver os problemas críticos da resistência microbiana e impedir os efeitos negativos dos compostos sintéticos tradicionalmente utilizados, e ao mesmo tempo atender aos requisitos de segurança alimentar e não exercer impacto negativo sobre os aspectos nutricionais e sensoriais dos alimentos.

Palavras-Chave: Antimicrobianos, biopreservação, compostos bioativos, conservantes naturais.

\footnotetext{
${ }^{1}$ Engenheira de Alimentos (Universidade de Passo Fundo - UPF), Doutora em Engenharia Química (UFSC), ellenfrodrigues@gmail.com;

${ }^{2}$ Engenheiro Agroindustrial-Agroquímico (Universidade Federal do Rio Grande - FURG), Estudante de mestrado em Engenharia Química (UFSC), afonso.silva@ posgrad.ufsc.br;

${ }^{3}$ Engenheiro Têxtil (Universidade Estadual de Maringá - UEM), Doutor em Engenharia Química (UFSC), carlos.oliveira@ufsc.br;

${ }^{4}$ Curso de Engenharia Química, Instituto Latino-Americano de Tecnologia, Infraestrutura e Território (ILATIT), Universidade Federal da Integração Latino-Americana (UNILA), luis.lourenco@ unila.edu.br;

${ }^{5}$ Engenheiro Ambiental (Universidade do Extremo Sul Catarinense - UNESC), Doutor em Ciência e Engenharia de Materiais (UFSC), lisandrosima@gmail.com;
} 


\title{
RESUMEN
}

La producción de alimentos seguros y de alta calidad se ha convertido en un desafío para la industria alimentaria, debido al deterioro de los alimentos, que es causado por el crecimiento indeseable de microorganismos patógenos/deteriorantes. Este deterioro puede provocar la pérdida y el desperdicio de alimentos. Para reducir las pérdidas, la industria alimentaria utiliza conservantes sintéticos para controlar el crecimiento microbiano con el fin de prolongar la vida útil, la calidad y la seguridad de los alimentos. Sin embargo, algunos aditivos químicos cuando se ingieren en grandes cantidades pueden causar reacciones indeseables a los consumidores. La creciente preferencia de los consumidores por aditivos alimentarios más naturales y la preocupación por la seguridad de los conservantes sintéticos han animado a la industria alimentaria a buscar alternativas ecológicas. Así, surgió la intención de sustituir el uso de conservantes sintéticos tradicionales por antimicrobianos naturales en los alimentos. El presente trabajo tiene como objetivo presentar algunos conservantes naturales con propiedades antimicrobianas, destacando la importancia de su uso en la producción de alimentos y sus posibles aplicaciones en los alimentos. Además, se presenta una clasificación basada en el origen de los antimicrobianos naturales considerando las fuentes de origen para las principales categorías: plantas, animales y microbianos. Las propiedades antimicrobianas de los compuestos de origen natural se deben principalmente a la presencia de sustancias bioactivas (como ácidos fenólicos, terpenos, aldehídos y flavonoides, entre otros). Estas sustancias bioactivas pueden considerarse una alternativa viable para solucionar los problemas críticos de resistencia microbiana y prevenir los efectos negativos de los compuestos sintéticos tradicionalmente utilizados, cumpliendo al mismo tiempo los requisitos de seguridad alimentaria y no teniendo un impacto negativo en la nutrición y sensoriales aspectos de los alimentos.

Palabras Clave: Antimicrobianos, biopreservación, compuestos bioactivos, conservantes naturales.

\begin{abstract}
The production of safe and high-quality food has become a challenge for the food industry, due to food spoilage, which is caused by the undesirable growth of pathogenic/deteriorating microorganisms. This deterioration can lead to the loss and waste of food. To reduce losses, the food industry uses synthetic preservatives to control microbial growth in order to extend shelf life, food quality, and safety. However, some chemical additives when ingested in large quantities can cause undesirable reactions to consumers. Increased consumer preference for more natural food additives and concern for the safety of synthetic preservatives have encouraged the food industry to look for environmentally friendly alternatives. Thus, the intention arose to replace the use of traditional synthetic preservatives with natural antimicrobials in foods. The present work aims to present some natural preservatives with antimicrobial properties, emphasizing the importance of their use in food production and possible applications in food. In addition, a classification based on the origin of natural antimicrobials is presented considering the sources of origin for the main categories: plants, animals, and microbial. The antimicrobial properties of compounds of natural origin are mainly due to the presence of bioactive substances (such as phenolic acids, terpenes, aldehydes, and flavonoids, among others). These bioactive substances can be considered a viable alternative to solve the critical problems of microbial resistance and to prevent the negative effects of synthetic compounds traditionally used, while at the same time meeting food safety requirements and not having a negative impact on the nutritional and sensory aspects of foods.
\end{abstract}

Keywords: Antimicrobials, biopreservation, bioactive compounds, natural preservatives. 


\section{INTRODUÇÃO}

Os produtos alimentícios naturais são perecíveis e necessitam de proteção contra a deterioração durante os processos de preparação, armazenamento e distribuição para ter uma vidá-útil de prateleira prolongada. A demanda por produtos alimentícios frescos minimamente processados representam um grande desafio para a segurança e a qualidade dos alimentos, devido estarem sujeitos à contaminação por microrganismos (bactérias e fungos) (FERREIRA et al., 2020).

A contaminação indesejada por microrganismos patogênicos e/ou deteriorantes podem causar reações que deterioram o sabor, o odor, a cor, as propriedades sensoriais dos alimentos, além de causa de doenças transmitidas por alimentos após a ingestão de alimentos contaminados (FERREIRA et al., 2020; QUINTO et al., 2019).

Em alimentos frescos minimamente processados o crescimento microbiano é afetado por diferentes fatores intrínsecos, como $\mathrm{pH}$ e presença de oxigênio ou por fatores extrínsecos associados às condições de armazenamento, incluindo temperatura, tempo e umidade relativa. Para inibir o crescimento desses microrganismos responsáveis pela deterioração de alimentos, a indústria de alimentos tem investido cada vez mais em métodos de preservação. Muitos dos métodos utilizados fazem uso de conservantes químicos e sintéticos por serem de baixo custo e de fácil obtenção (BASSOLÉ; JULIANI, 2012; SILVA; DOMINGUES, 2017).

No entanto, os conservantes sintéticos são conhecidos por causar problemas de saúde, podendo estar associados a possíveis efeitos cancerígenos ou reações alérgicas devido a presença de compostos como nitratos, benzoatos, sulfitos, sorbatos, formaldeído e antioxidantes fenólicos que são utilizados ((BASSOLÉ; JULIANI, 2012; SILVA; DOMINGUES, 2017; SOUZA et al., 2005; TIWARI et al., 2009).

Nos últimos anos, houve um crescimento na conscientação dos consumidores sobre a presença e utilização de aditivos químicos sintéticos nos alimentos, assim, o uso de alimentos conservados com aditivos naturais se tornaram mais populares. Muitos estudos têm sido realizados com o intuito de obter agentes conservantes de fontes naturais. Esses conservantes naturais devem prolongar a vida útil e garantir a segurança dos alimentos, além de substituir os conservantes sintéticos convencionalmente utilizados pelas indústrias alimentícias (BASSOLÉ; JULIANI, 2012; THIELMANN; KOHNEN; HAUSER, 2017) .

A utilização de conservantes naturais antimicrobianos (biopreservação) para garantir a segurança e a qualidade dos alimentos, pode ser uma alternativa a outros sistemas de preservação, como os químicos ou térmicos, além disso, sua incorporação direta a diversos 


\section{ANTIMICROBIANOS NATURAIS NA CONSERVAÇÃO DE ALIMENTOS}

alimentos de origens distintas, como carnes ou vegetais, bem como à sua embalagem, confere, como resultado, o prolongamento de sua vida útil de prateleira (AZIZ; KARBOUNE, 2016; GYAWALI; IBRAHIM, 2014; PISOSCHI et al., 2018).

A biopreservação utiliza conservantes naturais com o intuito de inibir o crescimento de inúmeros microrganismos patogênicos/deteriorantes em alimentos; esses conservantes naturais podem ser de origem animal, vegetal ou microbiana (bactérias, cogumelos, algas e vírus) (GYAWALI; IBRAHIM, 2014).

Considerando a abordagem descrita acima, observa-se o potencial da substituição dos conservantes sintéticos tradicionais utilizados na indústria de alimentos por antimicrobianos de origem natural. Nesta revisão, será apresentada uma visão geral dos antimicrobianos de origem natural, apresentando os seguintes tópicos: Antimicrobianos naturais de origem microbiana, animal e de plantas, e suas possíveis aplicações em alimentos. Os termos descritos nos tópicos foram pesquisados nas principais bases de dados e os principais artigos encontrados foram analisados e sintetizados de acordo com a abordagem proposta no presente trabalho.

\section{REFERENCIAL TEÓRICO}

\section{ANTIMICROBIANOS DE FONTES NATURAIS}

Os microrganismos patogênicos responsáveis pela deterioração de alimentos têm sido considerados uma das principais causas de doenças transmitidas por alimentos e diminuição da qualidade dos alimentos, o que resulta em muitas intoxicações alimentares e perdas econômicas significativas a cada ano (OVER et al., 2009).

Embora hoje a segurança alimentar seja uma preocupação mundial para a saúde, na maioria das vezes os aspectos de processamento e preservação de alimentos passam despercebidos não apenas nos países em desenvolvimento, mas também nos países desenvolvidos.

Dentre as técnicas de preservação disponíveis, está a aplicação de aditivos químicos e/ou conservantes que são usados para combater microrganismos patogênicos e deteriorantes que se desenvolvem nas superfícies dos alimentos. Porém atualmente, o aumento da conscientização sobre a saúde atraiu os consumidores para consumir alimentos naturais com maiores benefícios para a saúde sem conservantes químicos adicionados. Assim, a indústria de alimentos está enfrentando desafios devido às regulamentações rigorosas e à demanda dos consumidores por alimentos naturais com maior qualidade e vida útil de prateleira (LAHIRI et 
al., 2020).

A biopreservação (utilização de antimicrobianos naturais em alimentos) está focada no uso de conservantes naturais de fontes como bactérias, fungos, plantas, animais, tendo a capacidade de garantir a segurança alimentar devido à sua atividade antimicrobiana exercida contra um amplo espectro de microrganismos patogênicos e deteriorantes de origem alimentar (GYAWALI; IBRAHIM, 2014). A Figura 1 apresenta uma visão geral de alguns antimicrobianos naturais de fonte animal, vegetal ou microbiana que serão descritos nos subitens abaixo.

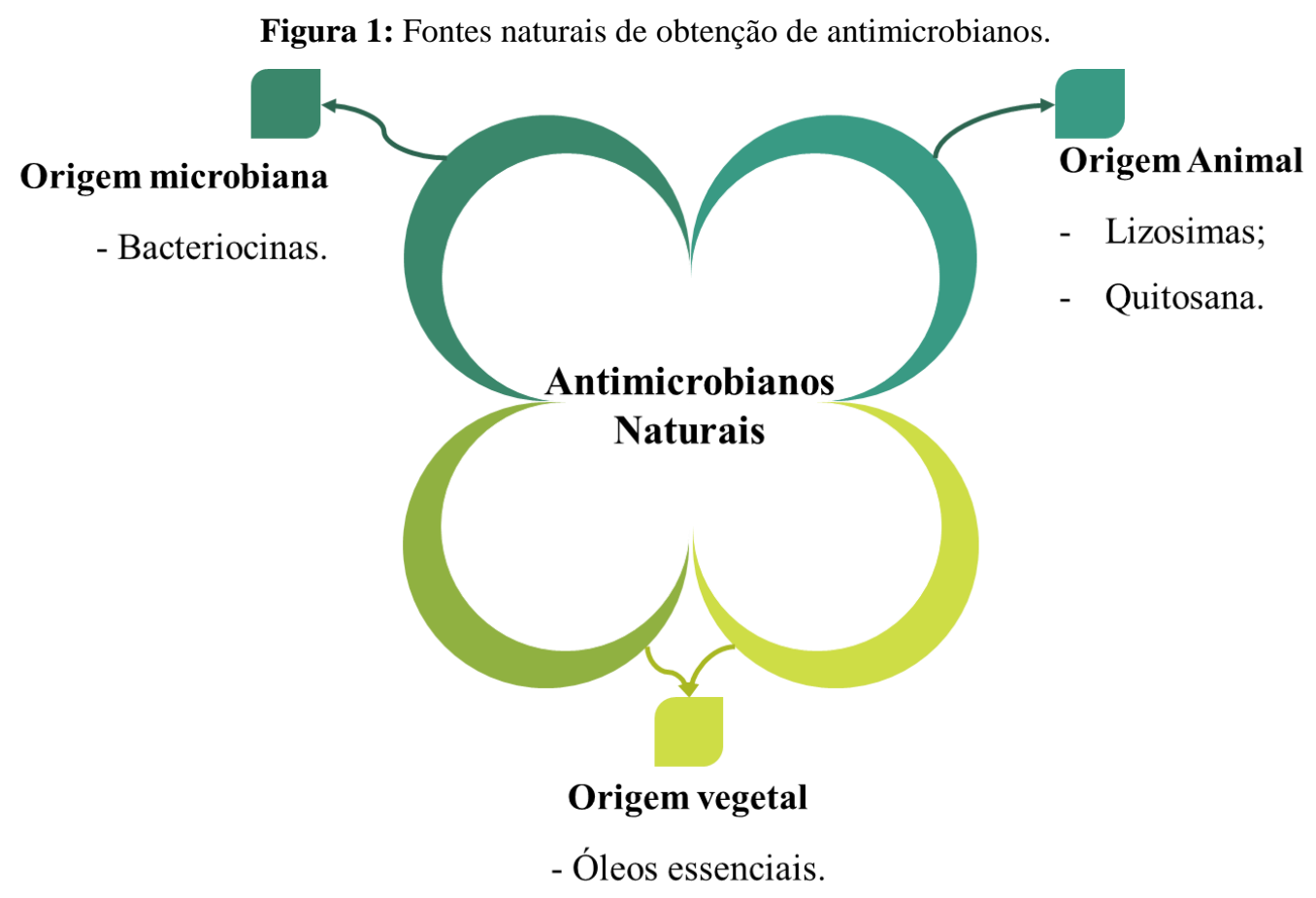

Fonte: Autores (2021).

\section{Antimicrobianos naturais de fontes microbianas}

Alguns microrganismos possuem a capacidade de produzir substâncias que podem ser responsáveis pela inibição de crescimento de outros microrganismos (Tabela 1). A produção de antimicrobianos por microrganismos é relatada desde os anos 50. Quando se fala o termo antimicrobiano, a maior ênfase é dada as bacteriocinas, que são peptídeos antimicrobianos sintetizados nos ribossomos e atuam contra bactérias Gram-positivas e Gram-negativas, sendo a bactéria produtora portadora de mecanismos de imunidade específicos que protegem a sua própria bacteriocina (COTTER; ROSS; HILL, 2013).

São bacteriocinas as nisinas, carnobacteriocinas, pediocinas, plantaricinas, lacticinas, 


\section{ANTIMICROBIANOS NATURAIS NA CONSERVAÇÃO DE ALIMENTOS}

enterocinas, lactococinas, leuconocinas, entre outras. Podendo ser classificadas em 4 classes de acordo com suas características bioquímicas e genéticas (Figura 2) (COTTER; ROSS; HILL, 2013).

Figura 2: Classificação das bacteriocinas

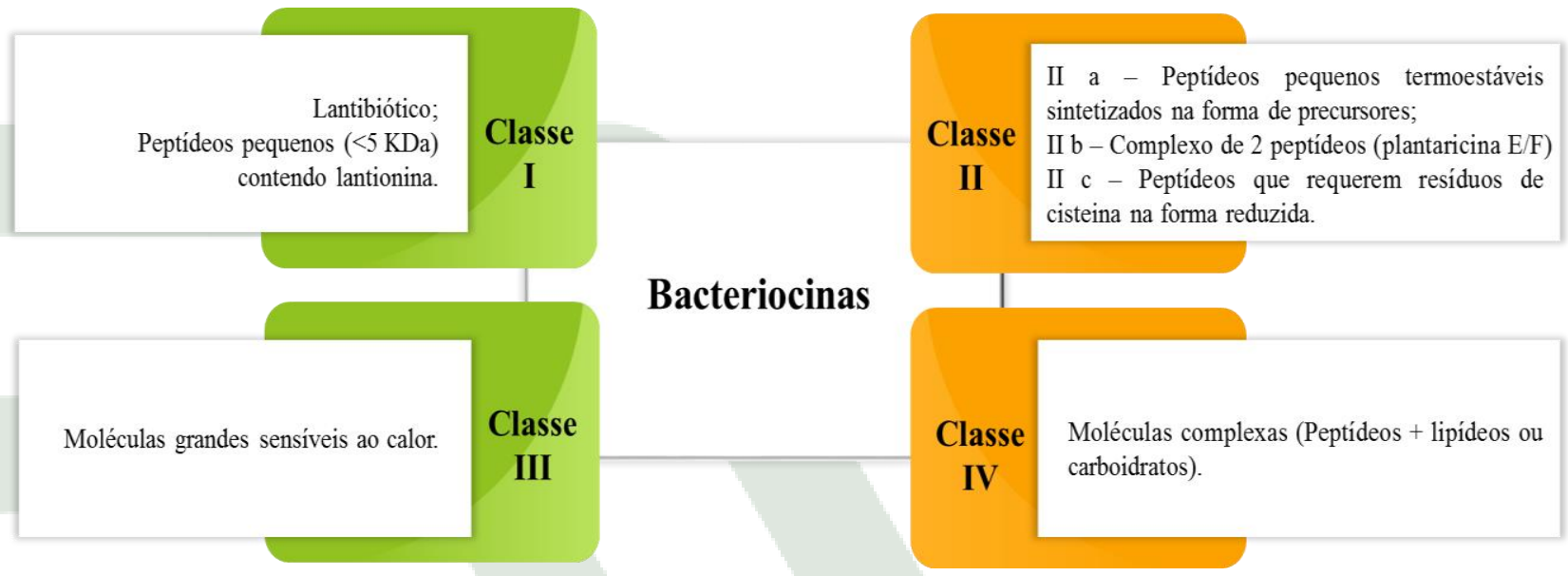

Fonte: Cotter, Ross e Hill (2013).

Em geral, as bacteriocinas são catiônicas e exibem propriedades anfipáticas, sendo a membrana bacteriana, na maioria das vezes, o alvo de sua atividade. São conhecidas diversos tipos de bacteriocinas, diferindo-se em tamanho, alvo microbiano, modo de ação, liberação e mecanismos de imunidade (GILLOR; ETZION; RILEY, 2008; OGAKI; FURLANETO; MAIA, 2015). Embora sejam conhecidas, a função estrutural, a biossíntese e o modo de ação de algumas bacteriocinas ainda permanecem desconhecidos.

As primeiras bacteriocinas descritas foram as colicinas de bactérias Gram-negativas (oriundas de Escherichia coli), as colicinas apresentaram capacidade de inteferir por efeito bactericida ou bacteriostático, no crescimento de outras bactérias de espécies relacionadas (OGAKI; FURLANETO; MAIA, 2015). Desde sua descoberta, as colicinas de Escherichia coli têm sido as bacteriocinas Gram-negativas mais estudadas, servindo como um sistema modelo para investigar os mecanismos de estrutura/função da bacteriocina, organização genética, ecologia e evolução (CASCALES et al., 2007). 
RODRIGUES, E. F. et al.

Tabela 1: Bacteriocinas utilizadas no controle do crescimento microbiano.

\begin{tabular}{ccc}
\hline Microrganismo produtor & Bacteriocina & Alvo microbiano \\
Bacillus sp. & Mersacidina & Streptococcus pneumonia \\
& & Staphylococcus aureus resistentes à meticilina \\
Lactococcus lactis & Nisina & Bacillus cereus \\
& & Streptococcus pneumoniae \\
Staphylococcus aureus & Aureocina A53 & Listeria monocytogenes \\
& & Streptococcus agalactiae \\
Staphylococcus hyicus & Hyicina 3682 & Listeria monocytogenes \\
& & Staphylococcus aureus \\
& & Bacillus cereus \\
\hline
\end{tabular}

Fonte: Cotter, Ross e Hill (2013); Xiang et al. (2021).

Estudos relacionados aos agentes antibacterianos naturais como bacteriocinas em aplicações alimentares tem atraído atenção, principalmente para as bacteriocinas derivadas do gênero Bacillus. As bacteriocinas obtidas a partir de Bacillus apresentam resistência a altas temperaturas e forte tolerância a ácido-base, indicando amplas perspectivas de aplicação para preservação e conservação de alimentos (XIANG et al., 2021).

Entre as substância antimicrobianas produzidas por microrganismos está a nisina. A nisina é o única substância com ação bactericida aprovada em mais de 50 países. É sintetizado por Lactoccocus lactis e atua contra bactérias Gram-positivas e formadoras de esporos. Os principais microrganismos que são inibidos pela nisina são patógenos Gram-positivos de origem alimentar ou bactérias deteriorantes como Staphylococcus aureus, Micrococcus luteus e Bacillus cereus (HONDRODIMOU; KOURKOUTAS; PANAGOU, 2011).

A nisina inibe também o crescimento de leveduras e bolores em alimentos como azeitonas, quando utilizada em combinação com a natamicina (HONDRODIMOU; KOURKOUTAS; PANAGOU, 2011). Apresenta atividade aumentada contra bactérias Grampositivas e controla o desenvolvimento de Clostridium spp. em queijo (O'SULLIVAN, 2012). O caráter catiônico geral dessa bacteriocina explica a geração de poros através das membranas celulares e a fácil interação com bactérias Gram-positivas que possuem níveis elevados de lipídios aniônicos na membrana (CHEN; HOOVER, 2003).

O ácido lático é o agente antimicrobiano predominante em sobrenadantes de bactérias láticas e é um dos principais ácidos orgânicos encontras em produtos fermentados, além de ser amplamente distribuído na natureza. Nos Estados Unidos o ácido lático é utilizado em alimentos e reconhecido como Generally Recognized as Safe (GRAS) (ALAKOMI et al., 2000).

A ação bactericida do ácido lático esta atribuída a moléculas não dissociadas presentes 


\section{ANTIMICROBIANOS NATURAIS NA CONSERVAÇÃO DE ALIMENTOS}

em pH 4,0 (40 \%) e em pH 3,60 (60 \%) (ALAKOMI et al., 2000). A dissociação ácida dentro da célula bacteriana é acompanhada pelo acúmulo de ânions tóxicos, estresse sobre a homeostase celular, inibição de reações metabólicas e dependendo da extensão do efeito gerado de inibição da divisão, até mesmo a morte. A ação antibacteriana dos ácidos orgânicos ocorre devido às suas formas não dissociadas, as quais têm como objetivo as funções metabólicas dos microrganismos, tais como a produção de proteína, a inibição de ATP e um aumento na pressão osmótica (ASKARI et al., 2012; KÖHLER; ASSEFA; REID, 2012; LUES; THERON, 2012).

Além do ácido lático, os ácidos acético e propiônico também apresentam mecanismo de biopreservação (ALAKOMI et al., 2000; STANOJEVIĆ-NIKOLIĆ et al., 2016).

\section{Antimicrobianos naturais de fonte animal}

Os agentes antimicrobianos de origem animal são caracterizados por polissacarídeos, lipídeos e peptídeos antimicrobianos como pleurocidina, lactoferrina, defensinas e protamina. Os peptídeos antimicrobianos são considerados uma alternativa viável como antimicrobiano, pois alguns desses compostos são capazes de destruir rapidamente as membranas da bicamada lipídica celular de microrganismos de crescimento rápido e, além do seu efeito antibacteriano contra bactérias Gram-positivas e Gram-negativas, também apresentam atividades antifúngicas e antivirais (AIRES et al., 2009; TIWARI et al., 2009).

As lisozimas de origem animal são amplamente distribuídas na natureza e apresentam ação antimicrobiana, essa enzima possui ação bactericina contra microrganismos que são responsáveis pela deterioração dos alimentos. A lisozima têm sido aplicada em diversos modelos de estudos devido a sua ampla capacidade de aplicação (BEAUSSART et al., 2021).

As principais aplicações são como conservantes para preservar frutas, vegetais, molhos e alimentos infantis. Também é capaz de inibir o desenvolvimento de esporos de Clostridium tyrobutyricum em queijos. As bactérias Gram-positivas são o principal alvo da lisozima, pois a parede celular é composta por peptidoglicanos (BEAUSSART et al., 2021; LEŚNIEROWSKI; YANG, 2021).

Outra substância de origem animal com função antimicrobiana é a quitosana, a quitosana é um polissacarídeo derivado da quitina, não antigênico, não tóxico e apresenta altas atividades antioxidantes e antimicrobianas. É um polímero natural abundante, presente no exoesqueleto de crustáceos, insetos, e artrópode. A quitosana é um ingrediente alimentar aprovado no Japão, Coréia, EUA e Europa (AHSAN et al., 2018).

As propriedades antimicrobianas da quitosana são dependentes de fatores essenciais, 
incluindo o tipo de patógeno, $\mathrm{pH}$ do meio, propriedades estruturais, fonte e concentração de quitosana (GOY; BRITTO; ASSIS, 2009). O pH do meio é um fator fundamental para a atividade antimicrobiana e os melhores valores são abaixo de 6,5. Provavelmente, esse comportamento é atribuído à presença de uma quantidade significativa de grupos amino no polímero, onde os grupos $\mathrm{NH}^{+3}$ carregados positivamente aumentam a ligação a constituintes da membrana das bactérias patogênicas que são carregadas negativamente (GOY; BRITTO; ASSIS, 2009; HOSSEINNEJAD; JAFARI, 2016).

A quitosana apresenta atividade antimicrobiana contra bactérias Gram-negativas (Salmonella typhimurium, Escherichia coli, Pseudomonas aeruginosa, Pseudomonas fluorescens, Vibrio parahaemolyticus, Enterobacter aerogenes e Vibrio cholera), bactérias Gram-positivas (Bacillus cereus, Staphylococcus aureus, Bacillus megaterium, Lactobacillus plantarum, Listeria monocytogenes, Lactobacillus brevis e Lactobacillus bulgaricus), além da atividade antimicrobiana, a quitosa possui atividade antifúngica contra fungos e leveduras, como Fusarium oxysporum, Botrytis cinerea, Rhizoctonia solani, Candida lambica, Phomopsis asparagi (ABD EL-HACK et al., 2020; GOY; BRITTO; ASSIS, 2009; HOSSEINNEJAD; JAFARI, 2016; SAHARIAH; MÁSSON, 2017).

\section{Antimicrobianos naturais derivados de plantas}

As plantas comestíveis, medicinais, fitoterápicas e os respectivos óleos essenciais e subprodutos como hidrossol, assim como metabólitos secundários, são capazes de retardar ou inibir o desenvolvimento de bactérias, leveduras e bolores. Esses antimicrobianos de origem natural podem ser encontrados e identificados a partir de vários componentes das folhas das plantas, cascas, caules, raízes, flores e frutos (ALEKSIC SABO; KNEZEVIC, 2019).

Os óleos essenciais são misturas naturais de hidrocarbonetos, contendo oxigênio (álcoois, aldeídos, cetonas, ácidos carboxílicos, ésteres, lactonas) e substâncias orgânicas contendo enxofre (sulfuretos, dissulfeto, trissulfuretos). São obtidos principalmente de plantas por destilação a vapor, extração com dióxido de carbono supercrítico, prensagem a frio ou extração (maceração). Geralmente apresentam um odor agradável e às vezes um sabor distinto e, portanto, são usados em quantidades significativas nas indústrias de aromatizantes e perfumaria (BURT, 2004; KELKAR et al., 2006).

As características antimicrobianas dos produtos derivados de plantas são geralmente acompanhadas por capacidades antioxidantes (devido aos derivados de ácido fenólico, como ácido cafeico, flavonóides, cumarinas, terpenóides, lignanas e polissacarídeos), que completa 


\section{ANTIMICROBIANOS NATURAIS NA CONSERVAÇÃO DE ALIMENTOS}

os benefícios farmacológicos desses extratos. A combinação dos potenciais antioxidantes e antimicrobianos em uma molécula o torna ainda mais eficaz para a biopreservação de alimentos (AZIZ; KARBOUNE, 2016; PISOSCHI et al., 2016).

Os efeitos antimicrobianos dos óleos essencias foram avaliados contra uma ampla gama de microrganismos ao longo dos anos, no entanto, os mecanismos de ação envolvidos ainda não foram completamente compreendidos. Vários mecanismos têm sido propostos para explicar as ações dos compostos químicos contidos nos óleos essenciais (BURT, 2004).

Pesquisadores propuseram que a ação antimicrobiana dos óleos essencias pode estar atribuída à sua capacidade de penetrar através das membranas bacterianas para o interior da célula e exibir atividade inibitória nas propriedades funcionais da célula e às suas propriedades lipofílicas (KELKAR et al., 2006; LI et al., 2011).

A natureza fenólica dos óleos essenciais também induz uma resposta antimicrobiana contra bactérias patogênicas transmitidas por alimentos. Os compostos fenólicos rompem a membrana celular resultando na inibição das propriedades funcionais da célula e, eventualmente, causam vazamento do conteúdo interno da célula. Os mecanismos de ação podem estar relacionados à capacidade dos compostos fenólicos de alterar a permeabilidade celular microbiana, danificar as membranas citoplasmáticas, interferir no sistema de geração de energia celular (ATP) e interromper a força motriz do próton. A permeabilidade interrompida da membrana citoplasmática pode resultar na morte celular (BAJPAI; BAEK; KANG, 2012; BURT, 2004; KELKAR et al., 2006; LI et al., 2011).

Entre as substâncias de origem vegetal estão os óleos cítricos que são aprovados como compostos geralmente reconhecidos como seguros (GRAS) pela Food and Drug Administration (FDA), devido ao seu papel natural como agentes aromatizantes em sucos cítricos. Aproximadamente 400 compostos de óleos cítricos já foram identificados e os principais fatores que podem afetar a sua composição são: tipo de cultivar, bem como dos métodos de separação e extração (CHIKHOUNE et al., 2013).

O óleo obtido do limão é rico em limoneno, e este têm se mostrado eficaz contra os microrganismos Staphylococcus aureus, Listeria monocytogenes, Salmonella enterica e Saccharomyces bayanus, bem como outros microrganismos. No entanto, como o limoneno é um produto químico muito hidrofóbico e, portanto, é difícil de dispersar na água, grandes concentrações devem ser usadas para que o limoneno seja eficaz nos alimentos; o limoneno também é suscetível à degradação oxidativa, que causa perda de atividade (CHIKHOUNE et al., 2013; LI; CHIANG, 2012; TAO et al., 2009).

Os óleos essenciais têm sido realatado como agentes antimicrobianos eficazes contra 
microrganismos patogênicos de origem alimentar, incluindo Escherichia coli O157:H7, Salmonella Typhimurium, Staphylococcus aureus, Listeria monocytogenes, Campylobacter, entre outros. Demonstrou-se na literatura que os antimicrobianos oriundos de plantas apresentam melhor atividade contra bactérias Gram-positivas do que Gram-negativas, sendo as bactérias mais resistentes Pseudomonas aeruginosa e Proteus mirabilis (CALLAWAY et al., 2011).

\section{APLICAÇÕES DOS ANTIMICROBIANOS NATURAIS EM ALIMENTOS}

\section{Antimicrobianos naturais de fontes microbianas}

A nisina é efetivamente usada pela indústria de queijos contra microrganismos resistentes ao calor, como Bacillus e Clostridium (TIWARI et al., 2009). Economou et al. (2009) testaram o uso de nisina incorporada sozinha ou em combinação com outros agentes antimicrobianos em produtos alimentícios. Sob condições de embalagem em atmosfera modificada, a vida útil da carne de frango fresca usando uma concentração de 500 $\mathrm{UI} / \mathrm{g}$ de nisina e $50 \mathrm{mM}$ de EDTA foi estendida por 13-14 dias quando comparada com as amostras de controle (sem tratamento).

Além da utilização de antimicrobianos de fontes microbianas nos alimentos, há uma tendência promissora para a aplicação de bacteriocinas produzidas por bactérias láticas em embalagens. Scannel et al. (2000) aplicaram Laticina 3147 e nisina (Nisaplin®) em embalagens de polietileno/poliamida e estas foram capazes de reduzir o crescimento de microrganismos Listeria innocua, Staphylococcus aureus e Lactococcus lactis em até 2 ciclos log em queijo embalado a vácuo durante o armazenamento em temperaturas de refrigeração.

Nesse tipo de embalagem, o sistema da embalagem é capaz de inibir o crescimento de microrganismos patogênicos e deteriorantes de alimentos, a fim de prolongar a vida útil do produto, manter a qualidade e segurança dos alimentos, através do aumento da fase de latência e redução da taxa de crescimento dos microrganismos. Estas embalagens inteligentes são obtidas incorporando compostos antimicrobianos ao material de embalagem e/ou usando polímeros antimicrobianos que atendem os requisitos das embalagens convencionais (LA STORIA, 2008).

A fim de controlar e inibir a deterioração de alimentos, o filme antimicrobiano da embalagem deve entrar em contato com a superfície do alimento para que as bacteriocinas possam se difundir para a superfície do produto, o que é acompanhado pela liberação gradual 


\section{ANTIMICROBIANOS NATURAIS NA CONSERVAÇÃO DE ALIMENTOS}

de bacteriocinas do filme da embalagem para a superfície do alimento. Isso é considerado uma vantagem sobre outros métodos de interação alimentar com bacteriocinas, como mergulhar e pulverizar alimentos com bacteriocinas, porque a bacteriocina pode ser diluída, desativada ou ter sua atividade reduzida pelos componentes dos alimentos (LA STORIA, 2008).

Duas técnicas têm sido comumente usadas para preparar filmes de embalagem à base de bacteriocina, a primeira é incorporar bacteriocinas diretamente em polímeros, como a incorporação de nisina em filmes de proteína biodegradáveis, e a segunda é incorporar bacteriocinas em filmes de embalagem por revestimento ou adsorção de bacteriocinas em superfícies de polímero. A maioria das investigações conduzidas usando ambas as técnicas resultaram em uma vida útil estendida dos produtos alimentícios porque contagem de microrganismos que deterioram os alimentos foram reduzidas (LA STORIA, 2008; PILEVAR et al., 2020).

\section{Antimicrobianos naturais de fonte animal}

A quitosana é um antimicrobiano de origem animal que vem sendo usado para prevenir a deterioração e atuar como um antioxidante natural devido à quelação de íons metálicos em alimentos contendo lipídios, prolongando assim a vida útil do produto (JEON; KAMIL; SHAHIDI, 2002).

Revestimentos comestíveis de quitosana e embalagens de alimentos comestíveis têm sido relatado em diversos estudos devido à sua capacidade de inibir o crescimento de diferentes cepas de fungos, exceto aqueles que incluem quitosana em sua parede celular. Os revestimentos/filmes comestíveis formam uma barreira protetora ao redor das frutas e vegetais que prolongam a vida útil de prateleira e podem ser consumidos junto com o produto revestido (GOY; BRITTO; ASSIS, 2009; JEON; KAMIL; SHAHIDI, 2002; RIBEIRO et al., 2007; SAHARIAH; MÁSSON, 2017).

Ribeiro et al. (2007) aplicaram um revestimento de quitosana comestível aos morangos após a colheita para prolongar a vida útil e investigaram as propriedades superficiais, molhabilidade e permeabilidade ao oxigênio. Verificou-se que o revestimento diminuiu a taxa de crescimento microbiano do morango em comparação com os experimentos controle (sem revestimento).

A eficácia da lisozima e do EDTA para a conservação de queijos mussarela foi estudada por Sinigaglia et al. (2008). O queijo mussarela foi embalado em salmoura que continha lisozima $\left(0,25 \mathrm{mg} \cdot \mathrm{mL}^{-1}\right)$ e diferentes quantidades de $\operatorname{EDTA}\left(10,20\right.$ e $\left.50 \mathrm{mmol} . \mathrm{L}^{-1}\right)$ e 
posteriormente foi armazenado a $4 \pm 1^{\circ} \mathrm{C}$ por 8 dias. $\mathrm{O}$ sistema de embalagem inibiu significativamente o crescimento de coliformes e Pseudomonadaceae, sem afetar as bactérias láticas benéficas presentes no produto.

Conte, Brescia e Del Nobile (2011) também avaliaram os efeitos da lisozima e do EDTA em queijos burrata embalados em embalagem com atmosfera modificada (95:5 $\left.\mathrm{CO}_{2}: \mathrm{N}_{2}\right)$, os resultados demonstraram que as substâncias são válidas para prolongar a vida útil do queijo, especialmente em altas concentrações de lisozima.

\section{Antimicrobianos naturais derivados de plantas}

Os óleos essenciais possuem atividades antibacterianas e antifúngicas contra vários microrganismos associados à carne, incluindo bactérias Gram-negativas e Gram-positivas. Muitos estudos foram realizados para examinar os efeitos dos óleos essenciais obtidos de fontes como orégano, alecrim, tomilho, sálvia, manjericão, açafrão, coentro, gengibre, alho, nozmoscada, cravo, maça, salgado e erva-doce, quando usados sozinho ou em combinação com outros óleos essenciais e/ou métodos de preservação, a fim de melhorar as qualidades sensoriais e estender a vida útil de carnes e produtos cárneos (GOULAS; KONTOMINAS, 2007; KARABAGIAS; BADEKA; KONTOMINAS, 2011).

O efeito antimicrobiano do óleo essencial extraído do tomilho em níveis de adição de 0,3\%, 0,6 \% ou 0,9\% sobre a bactéria Escherichia coli 0157:H7 foi investigado em carne picada por Solomakos et al. (2008). O tratamento da carne picada com óleo essencial de tomilho $(0,6 \%)$ inibiu o crescimento de Escherichia coli $\mathrm{O} 157: \mathrm{H} 7$ durante o armazenamento a $10{ }^{\circ} \mathrm{C}$, mas não a $4{ }^{\circ} \mathrm{C}$. Além disso, os pesquisadores observaram um efeito bacteriostático ou bactericida do óleo de tomilho em Escherichia coli O157: H7 em níveis baixos de 0,12 \% e $0,25 \%$, respectivamente (FRATIANNI et al., 2010).

Os óleos essenciais de tomilho e bálsamo apresentaram redução na contagem de microflora natural presente na carne de peito de frango. Isso evita a deterioração da carne de frango e prolonga a vida útil do produto fresco quando armazenado a $4{ }^{\circ} \mathrm{C}$. Óleo essencial de tomilho na concentração de $0,5 \%$ limitou significativamente o crescimento de Escherichia coli, enquanto o óleo essencial de bálsamo na concentração de $0,5 \%$ inibiu efetivamente o crescimento de Salmonella spp.; além disso, a carne de frango tratada com óleo de bálsamo e óleo de tomilho teve contagens microbianas totais mais baixas do que as amostras de controle (sem tratamento do óleo essencial). Foi relatado que a carne de frango tratado com óleo essencial de tomilho apresentou notável inibição do crescimento de bactérias do ácido lático até 


\section{ANTIMICROBIANOS NATURAIS NA CONSERVAÇÃO DE ALIMENTOS}

o final do armazenamento (FRATIANNI et al., 2010).

-Ur-Rehman et al. (2007) estudaram diferentes aplicações de óleos essenciais de casca de frutas cítricas (malta (Citrus sinensis) e mossumbi (Citrus sinensis)), em pães. Os resultados obtidos demonstraram que os óleos essenciais influenciaram as características sensoriais e retardaram o crescimento microbiano. O efeito inibitório máximo contra fungos (Aspergillus spp., Penicillium, Rhizopus e Neurospora) e bactérias foi alcançado pulverizando óleo essencial sobre a casca do pão.

\section{CONSIDERAÇÕES FINAIS}

Muitos produtos alimentícios frescos necessitam de técnicas de conservação que sejam seguras para melhorar a qualidade sem causar perdas nutricionais e organolépticas durante o armazenamento. Nesse contexto, a aplicação de antimicrobianos naturais vêm ganhando interesse da pesquisa e da indústria de alimentos, devido ao potencial de proporcionar benefícios de qualidade e segurança, com menor impacto a saúde humana. Além disso, a utilização de agentes ativos naturais promove os critérios aceitos de sustentabilidade alimentar. As diversas aplicações de óleos essenciais, enzimas, bacteriocinas, quitosanas e ácidos orgânicos nos alimentos perecíveis frescos são adequados para serem utilizados como conservantes em alimentos e podem ser uma alternativa atrativa aos aditivos alimentares sintéticos/químicos.

\section{REFERÊNCIAS}

-UR-REHMAN, S.; HUSSAIN, S.; NAWAZ, H.; MUSHTAQ AH, M.; ANJUM MURT, M.; JAFFAR RIZ, A. Inhibitory Effect of Citrus Peel Essential Oils on the Microbial Growth of Bread. Pakistan Journal of Nutrition, v. 6, n. 6, p. 558-561, 15 out. 2007.

ABD EL-HACK, M. E.; EL-SAADONY, M. T.; SHAFI, M. E.; ZABERMAWI, N. M.; ARIF, M.; BATIHA, G. E.; KHAFAGA, A. F.; ABD EL-HAKIM, Y. M.; AL-SAGHEER, A. A. Antimicrobial and antioxidant properties of chitosan and its derivatives and their applications: A review. International Journal of Biological Macromolecules, v. 164, p. 2726-2744, dez. 2020.

AHSAN, S. M.; THOMAS, M.; REDDY, K. K.; SOORAPARAJU, S. G.; ASTHANA, A.; BHATNAGAR, I. Chitosan as biomaterial in drug delivery and tissue engineering. International Journal of Biological Macromolecules, v. 110, p. 97-109, abr. 2018.

AIRES, A.; MOTA, V. R.; SAAVEDRA, M. J.; ROSA, E. A. S.; BENNETT, R. N. The antimicrobial effects of glucosinolates and their respective enzymatic hydrolysis products on 
bacteria isolated from the human intestinal tract. Journal of Applied Microbiology, v. 106, n. 6, p. 2086-2095, jun. 2009.

ALAKOMI, H.-L.; SKYTTÃ, E.; SAARELA, M.; MATTILA-SANDHOLM, T.; LATVAKALA, K.; HELANDER, I. M. Lactic Acid Permeabilizes Gram-Negative Bacteria by Disrupting the Outer Membrane. Applied and Environmental Microbiology, v. 66, n. 5, p. 2001-2005, 2000.

ALEKSIC SABO, V.; KNEZEVIC, P. Antimicrobial activity of Eucalyptus camaldulensis Dehn. plant extracts and essential oils: A review. Industrial Crops and Products, v. 132, p. 413-429, jun. 2019.

ASKARI, G. AL; KAHOUADJI, A.; KHEDID, K.; CHAROF, R.; MENNANE, Z. Screenings of lactic acid bacteria isolated from dried fruits and study of their antibacterial activity. Middle East Journal of Scientific Research, v. 11, n. 2, p. 209-215, 2012.

AZIZ, M.; KARBOUNE, S. Natural antimicrobial/antioxidant agents in meat and poultry products as well as fruits and vegetables: A review. Critical Reviews in Food Science and Nutrition, v. 58, n. 3, p. 1-26, 20 jul. 2016.

BAJPAI, V. K.; BAEK, K.-H.; KANG, S. C. Control of Salmonella in foods by using essential oils: A review. Food Research International, v. 45, n. 2, p. 722-734, mar. 2012.

BASSOLÉ, I. H. N.; JULIANI, H. R. Essential Oils in Combination and Their Antimicrobial Properties. Molecules, v. 17, n. 4, p. 3989-4006, 2 abr. 2012.

BEAUSSART, A.; RETOURNEY, C.; QUILÈS, F.; DOS SANTOS MORAIS, R.; GAIANI, C.; FIÉROBE, H. P.; EL-KIRAT-CHATEL, S. Supported lysozyme for improved antimicrobial surface protection. Journal of Colloid and Interface Science, v. 582, p. 764$772,2021$.

BURT, S. Essential oils: their antibacterial properties and potential applications in foods-a review. International Journal of Food Microbiology, v. 94, n. 3, p. 223-253, ago. 2004.

CALLAWAY, T. R.; CARROLL, J. A.; ARTHINGTON, J. D.; EDRINGTON, T. S.; ANDERSON, R. C.; RICKE, S. C.; CRANDALL, P.; COLLIER, C.; NISBET, D. J. Citrus Products and Their Use Against Bacteria: Potential Health and Cost Benefits. In: Nutrients, Dietary Supplements, and Nutriceuticals. Totowa, NJ: Humana Press, 2011. p. 277-286.

CASCALES, E.; BUCHANAN, S. K.; DUCHÉ, D.; KLEANTHOUS, C.; LLOUBÈS, R.; POSTLE, K.; RILEY, M.; SLATIN, S.; CAVARD, D. Colicin Biology. Microbiology and Molecular Biology Reviews, v. 71, n. 1, p. 158-229, mar. 2007.

CHEN, H.; HOOVER, D. G. Bacteriocins and their Food Applications. Comprehensive Reviews in Food Science and Food Safety, v. 2, p. 82-100, 2003.

CHIKHOUNE, A.; HAZZIT, M.; KERBOUCHE, L.; BAALIOUAMER, A.; AISSAT, K. Tetraclinis articulata (Vahl) Masters essential oils: chemical composition and biological activities. Journal of Essential Oil Research, v. 25, n. 4, p. 300-307, ago. 2013. 
CONTE, A.; BRESCIA, I.; DEL NOBILE, M. A. Lysozyme/EDTA disodium salt and modified-atmosphere packaging to prolong the shelf life of burrata cheese. Journal of Dairy Science, v. 94, n. 11, p. 5289-5297, nov. 2011.

COTTER, P. D.; ROSS, R. P.; HILL, C. Bacteriocins - a viable alternative to antibiotics? Nature Reviews Microbiology, v. 11, n. 2, p. 95-105, 24 fev. 2013.

ECONOMOU, T.; POURNIS, N.; NTZIMANI, A.; SAVVAIDIS, I. N. Nisin-EDTA treatments and modified atmosphere packaging to increase fresh chicken meat shelf-life. Food Chemistry, v. 114, n. 4, p. 1470-1476, jun. 2009.

FERREIRA, M. J. G.; NOGUEIRA, P. C. D. N.; DIAS, F. G. B.; SILVA, L. M. R. DA; SILVEIRA, E. R.; FIGUEIREDO, E. A. T. DE. Antimicrobial activity and chemical characterization of the bark decoction of cumaru stem. Ciência Rural, v. 50, n. 3, p. 1-6, 2020 .

FRATIANNI, F.; DE MARTINO, L.; MELONE, A.; DE FEO, V.; COPPOLA, R.; NAZZARO, F. Preservation of Chicken Breast Meat Treated with Thyme and Balm Essential Oils. Journal of Food Science, v. 75, n. 8, p. M528-M535, out. 2010.

GILLOR, O.; ETZION, A.; RILEY, M. A. The dual role of bacteriocins as anti- and probiotics. Applied Microbiology and Biotechnology, v. 81, n. 4, p. 591-606, 1 dez. 2008.

GOULAS, A. E.; KONTOMINAS, M. G. Combined effect of light salting, modified atmosphere packaging and oregano essential oil on the shelf-life of sea bream (Sparus aurata): Biochemical and sensory attributes. Food Chemistry, v. 100, n. 1, p. 287-296, jan. 2007.

GOY, R. C.; BRITTO, D. DE; ASSIS, O. B. G. A review of the antimicrobial activity of chitosan. Polímeros, v. 19, n. 3, p. 241-247, 2009.

GYAWALI, R.; IBRAHIM, S. A. Natural products as antimicrobial agents. Food Control, v. 46, p. 412-429, dez. 2014.

HONDRODIMOU, O.; KOURKOUTAS, Y.; PANAGOU, E. Z. Efficacy of natamycin to control fungal growth in natural black olive fermentation. Food Microbiology, v. 28, n. 3, p. 621-627, maio 2011.

HOSSEINNEJAD, M.; JAFARI, S. M. Evaluation of different factors affecting antimicrobial properties of chitosan. International Journal of Biological Macromolecules, v. 85, p. 467475, abr. 2016.

JEON, Y.-J.; KAMIL, J. Y. V. A.; SHAHIDI, F. Chitosan as an Edible Invisible Film for Quality Preservation of Herring and Atlantic Cod. Journal of Agricultural and Food Chemistry, v. 50, p. 5167-5178, 2002.

KARABAGIAS, I.; BADEKA, A.; KONTOMINAS, M. G. Shelf life extension of lamb meat using thyme or oregano essential oils and modified atmosphere packaging. Meat Science, v. 88, n. 1, p. 109-116, maio 2011. 
KELKAR, V. M.; GEILS, B. W.; BECKER, D. R.; OVERBY, S. T.; NEARY, D. G. How to recover more value from small pine trees: Essential oils and resins. Biomass and Bioenergy, v. 30, n. 4, p. 316-320, abr. 2006.

KÖHLER, G. A.; ASSEFA, S.; REID, G. Probiotic Interference of Lactobacillus rhamnosus GR-1 and Lactobacillus reuteri RC-14 with the Opportunistic Fungal Pathogen Candida albicans. Infectious Diseases in Obstetrics and Gynecology, v. 2012, n. 4, p. 1-14, 2012.

LA STORIA, A. Development and application of antimicrobial food packaging. [s.l.] UNIVERSITÀ DEGLI STUDI DI NAPOLI FEDERICO II, 2008.

LAHIRI, D.; CHAKRABORTI, S.; JASU, A.; NAG, M.; DUTTA, B.; DASH, S.; RAY, R. R. Production and purification of bacteriocin from Leuconostoc lactis SM 2 strain. Biocatalysis and Agricultural Biotechnology, v. 30, n. October, p. 101845, nov. 2020.

LEŚNIEROWSKI, G.; YANG, T. Lysozyme and its modified forms: A critical appraisal of selected properties and potential. Trends in Food Science \& Technology, v. 107, n. August 2020, p. 333-342, jan. 2021.

LI, M.; MUTHAIYAN, A.; A. O’BRYAN, C.; E. GUSTAFSON, J.; LI, Y.; G. CRANDALL, P.; C. RICKE, S. Use of Natural Antimicrobials from a Food Safety Perspective for Control of Staphylococcus aureus. Current Pharmaceutical Biotechnology, v. 12, n. 8, p. 12401254, 1 ago. 2011.

LI, P.-H.; CHIANG, B.-H. Process optimization and stability of d-limonene-in-water nanoemulsions prepared by ultrasonic emulsification using response surface methodology. Ultrasonics Sonochemistry, v. 19, n. 1, p. 192-197, jan. 2012.

LUES, J. F. R.; THERON, M. M. Antimicrobials Against Selected Poultry-Borne Listeria monocytogenes Strains In Vitro. FOODBORNE PATHOGENS AND DISEASE, v. 9, n. 12, p. 1126-1129, 2012.

O’SULLIVAN, D. J. Developing antimicrobial dairy ingredients. Food Technology Magazine, p. 44-50, 2012.

OGAKI, M. B.; FURLANETO, M. C.; MAIA, L. F. Revisão: Aspectos gerais das bacteriocinas. Brazilian Journal of Food Technology, v. 18, n. 4, p. 267-276, dez. 2015.

OVER, K. F.; HETTIARACHCHY, N.; JOHNSON, M. G.; DAVIS, B. Effect of Organic Acids and Plant Extracts on Escherichia coli O157:H7, Listeria monocytogenes, and Salmonella Typhimurium in Broth Culture Model and Chicken Meat Systems. Journal of Food Science, v. 74, n. 9, p. M515-M521, nov. 2009.

PILEVAR, Z.; HOSSEINI, H.; BEIKZADEH, S.; KHANNIRI, E.; ALIZADEH, A. M. Application of Bacteriocins in Meat and Meat Products: An Update. Current Nutrition \& Food Science, v. 16, n. 2, p. 120-133, 14 fev. 2020.

PISOSCHI, A. M.; POP, A.; CIMPEANU, C.; PREDOI, G. Antioxidant Capacity Determination in Plants and Plant-Derived Products: A Review. Oxidative Medicine and Cellular Longevity, v. 2016, p. 1-36, 2016. 


\section{ANTIMICROBIANOS NATURAIS NA CONSERVAÇÃO DE ALIMENTOS}

PISOSCHI, A. M.; POP, A.; GEORGESCU, C.; TURCUŞ, V.; OLAH, N. K.; MATHE, E. An overview of natural antimicrobials role in food. European Journal of Medicinal Chemistry, v. 143, p. 922-935, jan. 2018.

QUINTO, E. J.; CARO, I.; VILLALOBOS-DELGADO, L. H.; MATEO, J.; DE-MATEOSILLERAS, B.; REDONDO-DEL-RÍO, M. P. Food Safety through Natural Antimicrobials. Antibiotics, v. 8, n. 4, p. 208, 31 out. 2019.

RIBEIRO, C.; VICENTE, A. A.; TEIXEIRA, J. A.; MIRANDA, C. Optimization of edible coating composition to retard strawberry fruit senescence. Postharvest Biology and Technology, v. 44, n. 1, p. 63-70, abr. 2007.

SAHARIAH, P.; MÁSSON, M. Antimicrobial Chitosan and Chitosan Derivatives: A Review of the Structure-Activity Relationship. Biomacromolecules, v. 18, n. 11, p. 3846-3868, 13 nov. 2017.

SCANNELL, A. G. .; HILL, C.; ROSS, R. .; MARX, S.; HARTMEIER, W.; ARENDT, E. K. Development of bioactive food packaging materials using immobilised bacteriocins Lacticin 3147 and Nisaplin®. International Journal of Food Microbiology, v. 60, n. 2-3, p. 241249, set. 2000.

SILVA, F.; DOMINGUES, F. C. Antimicrobial activity of coriander oil and its effectiveness as food preservative. Critical Reviews in Food Science and Nutrition, v. 57, n. 1, p. 35-47, 2 jan. 2017.

SINIGAGLIA, M.; BEVILACQUA, A.; CORBO, M. R.; PATI, S.; DEL NOBILE, M. A. Use of active compounds for prolonging the shelf life of mozzarella cheese. International Dairy Journal, v. 18, n. 6, p. 624-630, jun. 2008.

SOLOMAKOS, N.; GOVARIS, A.; KOIDIS, P.; BOTSOGLOU, N. The antimicrobial effect of thyme essential oil, nisin and their combination against Escherichia coli O157:H7 in minced beef during refrigerated storage. Meat Science, v. 80, n. 2, p. 159-166, out. 2008.

SOUZA, E. L. DE; STAMFORD, T. L. M.; LIMA, E. DE O.; TRAJANO, V. N.; BARBOSA FILHO, J. M. Antimicrobial effectiveness of spices: an approach for use in food conservation systems. Brazilian Archives of Biology and Technology, v. 48, n. 4, p. 549-558, jul. 2005.

STANOJEVIĆ-NIKOLIĆ, S.; DIMIĆ, G.; MOJOVIĆ, L.; PEJIN, J.; DJUKIĆ-VUKOVIĆ, A.; KOCIĆ-TANACKOV, S. Antimicrobial Activity of Lactic Acid Against Pathogen and Spoilage Microorganisms. Journal of Food Processing and Preservation, v. 40, n. 5, p. 990-998, out. 2016.

TAO, N. G.; LIU, Y. J.; TANG, Y. F.; ZHANG, J. H.; ZHANG, M. L.; ZENG, H. Y. Essential oil composition and antimicrobial activity of Citrus reticulata. Chemistry of Natural Compounds, v. 45, n. 3, p. 437-438, 12 maio 2009.

THIELMANN, J.; KOHNEN, S.; HAUSER, C. Antimicrobial activity of Olea europaea Linné extracts and their applicability as natural food preservative agents. International Journal of Food Microbiology, v. 251, p. 48-66, jun. 2017. 
TIWARI, B. K.; VALDRAMIDIS, V. P.; O’ DONNELL, C. P.; MUTHUKUMARAPPAN, K.; BOURKE, P.; CULLEN, P. J. Application of Natural Antimicrobials for Food

Preservation. Journal of Agricultural and Food Chemistry, v. 57, n. 14, p. 5987-6000, 22 jul. 2009.

XIANG, Y.-Z.; ZHANG, Y.-M.; LIU, Y.-Y.; ZHANG, M.; LIN, L.-B.; ZHANG, Q.-L.

Purification, characterization, and antibacterial and antibiofilm activity of a novel bacteriocin against Salmonella Enteritidis. Food Control, v. 127, n. February, p. 108110, set. 2021. 